\title{
Interspecies Pedagogy: What Could a Horse Teach Me About Teaching?
}

\author{
BILJANA CULIBRK FREDRIKSEN \\ Faculty of Humanities, Sports and Educational Science, \\ University of South-Eastern Norway \\ Biljana.C.Fredriksen@usn.no
}

\begin{abstract}
This article explores experiential learning through a more-than-human perspective. It builds on my earlier study of young children's experiential learning, which revealed the biological predispositions or"embodied capacities" that young children have to learn from experience. In this current investigation, I identify some characteristics of a horse's experiential learning and maintain that understanding these experiences is relevant for teaching beyond human perspectives. I also seek to understand how a teacher can motivate experiential learning. The article presents an ethnographic case study of myself and my horse Zvekki. Zvekki's sophisticated predispositions for experiential learning have become visible over the years I have been pursuing a relationship of mutual trust between us. Daily interactions with Zvekki have challenged my communicative and other skills to the full and facilitated conditions for both her and my own experiential learning. The joint learning has also been a process of gaining more respect for the horse and gradually moving away from the anthropocentric position where, I realise retrospectively, I started from. What my horse taught me is relevant for teaching different subjects within teacher education programmes because every learning process and form of teaching is an experience in itself. The article focuses on the qualities of learning experiences and skills that are required from teachers who genuinely want to understand learning processes of their students and seek to provide conditions for holistic forms of learning.
\end{abstract}

KEYWORDS: horses; teaching; experiential learning

www.tsv.fi/tunnus 


\section{Introduction}

Learning through experience is necessary for survival. From an evolutionary perspective, human capacities for experiential learning, such as senses and emotions, are shared with other animals and grounded in the genetics of our common ancestors. New neuropsychological discoveries reject our earlier assumptions that humans are unique in the animal world; "cognition, emotions, ethics, decision-making, a sense of self, the capacity to suffer psychologically, and vocal learning" are similar for humans and other animals (Bradshaw 2010, 409). However, humans often rely on verbal forms of knowledge transmission, while other species learn explicitly from first-hand experience.

Formal education frequently teaches us to ignore our own embodied ways of learning (Fredriksen 2018). Studying animal experiential learning can therefore help us understand issues difficult to grasp through studying human education. Animals can often help us to better understand our human nature (Bradshaw 2009). However, to be able to learn from other living creatures we have to shift from an anthropocentric to a biocentric lens (De Georgio \& De Georgio-Schoorl 2016). In our performance-oriented societies, we often forget to listen to our own intrinsic state and motivation (De Georgio \& De Georgio-Schoorl 2016) and, from the perspective of a teacher, to our students' senses, emotions and curiosity as driving forces behind their inner will to learn. Many fellow teachers are struggling to resist the performance-oriented trends and striving to facilitate meaningful learning conditions for our more-than-human students. This article seeks to answer the following question: Which characteristics of more-thanhuman learner's experiences should be taken into consideration by teachers who seek to facilitate meaningful learning conditions?

This article presents a case of More-than-Human Participatory Research (Bastian et al. 2017) where my mare, Zvekki, and I learnt together. It is a case of "interspecies pedagogy" in which we learnt from each other about issues relating to teaching and learning. What I learnt from Zvekki was surprisingly similar to what I learnt during my study of young children's (2-5 years) experiential learning (Fredriksen 2011a, 2011b, 2012, 2016a, 2017, 2018). The embodied capacities for learning through experiences, which I discovered in co-research with children, were not only present in Zvekki, but sophisticated, vibrant and impossible to overlook (indeed dangerous to overlook). Teaching Zvekki demanded refined attention to emotional qualities of her past and present experiences, and to our inter-subjective communication (Fredriksen 2016b). This refinement of my attention in turn initiated complex processes of my ecological awareness. The article illustrates how teaching and learning can be understood in an 
ecologically holistic epistemology.

As a teacher of Art \& Craft in teacher education, I am looking at experiential learning from the point of aesthetic education, where individual uniqueness, emotions and senses are appreciated (Eisner 2002). Through this world view and approach this article challenges the established narrative of efficiency and objectivity of learning and the image of industrial production of knowledge (Robinson 2016).

Formal learning is not expected to be experiential, yet every learning situation is a source of experience. Any learning process leaves marks on a student, though not necessarily the marks a teacher hopes to leave. Students of any age and species learn much more than their teachers believe they are teaching them (Feinberg \& Soltis 2009). If teachers are more sensitive to their students' experiences and attentive to qualities of teaching contexts, they might be better able to provide conditions for learning that are more attuned to each student. Narratives from encounters with Zvekki illustrate the complexity of her learning process and what being attuned with her demanded. The article proposes that educational practices characterised by respect for more-than-human learners' experiences, uniqueness and creativity, have capacity to empower them and affect the quality of their lives.

\section{Connecting diverse perspectives}

\subsection{Experiential learning}

Experience is a result of "a complex interaction between body, sensory input, and neurological processes" (Fox 2008, 41). It is a unity of practical, intellectual and emotional dimensions (Dewey 2005) where "mind and body act in unison and are glued together" (Braidottl 2002, 135). Experience is therefore personal, subjective and individual, at the same time as it is shaped by cultures one has been a part of (Eisner, 2002); experiences are individual because they are "lived" through the individual body (Roberts 2008, 25). Each experience is unique, thus the ability to experience and make sense on the basis of the experience is common among more-than-humans (De Georgio \& De GeorgioSchoorl 2016).

Experiential learning can be seen as a continual process of negotiating personal understandings in specific contexts that are influenced by whatever participants (human and non-human) bring to the contexts: their past experiences, interests, interaction qualities or affordances of the physical environments (Fredriksen 2011). People, animals, objects and materials, each with their own advocacies, are, through intra-ac- 
tions, pulling and pushing toward new understandings (Barad 2007; Lenz Taguchi, Moss \& Dahlberg 2010). The activity of dealing with external challenges, especially a practical challenge that demands physical action, provokes each individual's inner transformation of thoughts, emotions, understandings, memories (Dewey 2005). The external and inner transformation processes are inextricable. While it is usually only the external process that is visible to others, the inner process can also be visible in individuals, who do not hold back their emotional reactions.

Experiential education has usually focused on verbal translations of human experiences (Fox 2008, 42). However, language is not an appropriate tool to represent the world - language frames how we can think about the world, it intervenes and invades the world (Braidotti 2002). This article focuses on experiential learning beyond verbal language. This broader perspective attempts to employ a less anthropocentric discourse in which the communication of animals can be heard. When nonverbal forms of learning are given a platform, animals can help us grasp how the more-than-human biological predispositions for learning through experience function.

\subsection{Emotions in learning}

A learning process is deeply grounded in emotions. It is, indeed, the emotional side of an experience that makes it possible to think without being aware of the thinking where "thinking is just like breathing" (Braidotti 2002, 125). Memory, attention and learning are hardly possible without emotions. Still, it is extremely hard to convince people to genuinely accept that emotions are essential for learning (Sterling 2011). The inability to accept emotions as significant for learning is probably a consequence of the dominant dualistic discourse where "true knowledge" is believed to be objective, unspoiled by emotions and pure from subjectivities. However, knowledge is always subjective and emotionally loaded as long as it is developed by someone alive, human or more-than-human.

The significance of emotions and embodiment has attracted interest in recent studies of human-animal relationship (Schuurman \& Sireni 2016; Bradshaw 2009). Emotions are an eminent part of more-than-humans' neural systems. Without ability to connect emotionally to their caregivers, babies (more-than-human) would not be able to survive (Dissanayake 2007). Emotions secure the survival of the species by facilitating care, protection and possibilities to learn from those one trusts.

Verbal language is a poor medium for communicating emotional nuances, whereas non-verbal communication constitutes the primary medium of transmitting 
emotions in more-than-humans (Bradshaw 2010). Inter-subjectivity is an ability to share emotions non-verbally (Stern 1998). We are able to "match other people's [and more-than-humans'] moods and emotions because of our ability to 'read' the form, the vitality, and the intensity of their movements" (Herskind 2008). Sharing attention, emotions and intentions between individuals is necessary in order to communicate inter-subjectively (Stern 1998), but it is only possible between individuals that are familiar with the same spectre of emotions, disregarding divisions in species. "We, humans and nonhumans, are hardwired to be sympathetic - to feel with each other, species being no barrier" (Shapiro \& DeMello 2010, 312). Horses, for instance, are particularly able to connect with human emotions, to read body language, and to perceive a millimetre of change in a facial expression (Wendt 2012).

\subsection{Teaching for experiential learning}

As teachers we are daily influencing our students' experiences. In primary education in Norway, teachers are required to consider each student's needs in curricula planning. Even though this sometimes seems impossible, I will argue that it is more likely that we meet the students' needs if we are more attentive and flexible during the teaching, rather that more expansive with the planning. The kinds of experiences we facilitate for our students depend not only on what we say, but rather more on how we speak, act and move - how we transmit socio-emotional information beneath our level of awareness (Bradshaw 2010).

A teacher who appreciates the uniqueness of each student can provide conditions for certain kinds of learning, but can never be sure what will be learnt (Eisner 2002). The impossibility to know what will be learnt is a consequence of the fact that experiences are born in moment-to-moment interactions (Birke 2017). "Momentary meetings" between a learner and a teacher are decisive for what can happen next (Aspelin 2010). Teachers need to be able to grasp "moments of contingency" (Smith 2011), and to take quick decisions that match the needs of their students (Biesta 2013). Teachers have to be highly attentive to their students' experiences and capable of undertaking pedagogical improvisations. Such improvisation is an intuitive capability to adapt tacit knowledge and apply it to new situations (Flyvbjerg 1992).

Coping with unpredictability of the processes of teaching is challenging. However, teachers can learn to enjoy "the beautiful risk of education" (Biesta 2013, 1) and "love enigmatic problems" (Austen 2014, 25). It is indeed exactly the challenge that makes growth possible, and this concerns both teacher and student (Eisner 2002): No 
challenge - no growth (Eisner 2002). Additionally, the level of challenge has to match exactly the learner's possibility to master the challenge with appropriate efforts: No mastery - no growth (Eisner 2002). Thus, the most important questions in providing conditions for learning are: What is an appropriate challenge?, and what is a suitable effort? The level of challenge is not about what the individual is generally capable of mastering, but what the individual is ready to master in their specific contexts and their specific emotional mood.

Teachers' abilities to provide appropriate conditions for experiential learning lie in their inter-subjectivity, care, attention, engagement and creativity, as well as awareness of power relations. These are exactly the qualities that were put to the test during my efforts to teach my physically dominant and emotionally distressed horse. My initial intention to be her teacher soon shifted to becoming her student. Our relationship gradually developed into co-learning through joint experiences, ongoing interpretations, challenges, improvisations and being attuneed to each other. We were "becoming-with" each other (Haraway 2008).

\subsection{More-than-human perspectives}

The interdisciplinary field that addresses relations among more-than-humans has recently "exploded" (Shapiro \& DeMello 2010). Diverse studies build on the theoretical foundation from critical pedagogy, post-humanism, trans-species psychology, humananimal studies, critical animal studies, animal welfare science, human ethology and multispecies ethnography (Davis \& Maurstad 2016a). Studies within these theoretical foundations are critical of the human-animal dualism that characterises much of human reasoning, and of anthropocentrism developed within academia (Shapiro \& DeMello 2010). One of the agendas of human-animal studies is to establish a more eco-centered paradigm (Shapiro \& DeMello 2010) that can contribute to more sustainable life on Earth for all animals, including humans.

Education is deeply grounded in those ideas of humanity in which "becoming human" equates with the cultivation of certain cognitive, social and moral abilities that define us as other-than-animals (Pedersen 2010). However, such cultivation has, in many ways, worked against our "human nature" that connects us with other animals. Similar to humans, other animals also learn "through listening, imitating, and experiencing their family and friends" (Bradshaw 2010, 413). A number of animal species have learned from us, been domesticated, been made into our companions and been contaminated by us (Armstrong \& Simmons 2007). They are never free from us, but we are 
never free from them either - we are all companions though our evolutionary history (Shapiro \& DeMello 2010, 312). Luckily, some animals are "resistant to our philosophies, theologies, representations, interests, intentions" (Armstrong \& Simmons 2007, 2), so we still have a chance to learn from them about our common nature hidden behind the layers of human contamination. The horse presented in this article offered such resistance during the most "rebellious" time of her life.

\subsection{Cognitive horse}

Humans and horses have played important roles in each other's lives during their 5000 year long history of companionship (Wendt 2012). Horses have been, and still are, valued for their usefulness to people, but unfortunately seldom valued as individuals with their own quality of life. Horses are often treated stereotypically, as if every horse was the same "instinct machine", but each individual has a unique world of experience, emotions and conscious thinking (Wendt 2011). Zooanthropology is a study field that "opens up a new model of interpretation and application in the dynamics of animal learning, recognizing animal subjectivity and alterity" (De Georgio \& De GeorgioSchoorl 2016, 16).

Each horse is born with cognitive abilities to understand her/himself, others and their environments; however, when being exposed to anthropocentric values, horses often lose their socio-cognitive abilities (De Georgio \& De Georgio-Schoorl 2016). A healthy horse is curious and driven by her/his intrinsic motivation to explore surroundings and relate to other subjects (De Georgio \& De Georgio-Schoorl 2016). Such intrinsic motivation is similar to what I found to be the most significant (embodied, "biological") force behind children's motivation for learning and creativity (Fredriksen 2011). This is also addressed as an "inner will" to act upon one's own environment (MerleauPonty 1962).

When horses are given "room for freedom of expression and inner motivation" (De Georgio \& De Georgio-Schoorl 2016, 36), they can have a learning space for their explorative and creative behaviour, which is driven by their intrinsic will to learn. In contrast, situations that are characterised by social isolation, by no space for explorative moments, by living in a non-familiar group or under performance expectations can cause reactive behaviour (De Georgio \& De Georgio-Schoorl 2016). Fulfilling human needs of ten demands obedience and the suppressing of cognitive capacities. Moreover, when horses live in contexts where their needs are not respected, their delicate ability to communicate gets damaged (De Georgio \& De Georgio-Schoorl 2016). They can 
grow numb and disinterested, develop reactive behaviour or become "time bombs" (De Georgio \& De Georgio-Schoorl 2016). Aggression in horses is almost always caused by behaviour and attitudes of their caregivers or trainers (Bradshaw 2010). A horse will rely and trust humans who radiate honest emotions, inner strength and peacefulness (Wendt 2012). Building an ethical and sustainable relationship with a horse demands mutual trust (Wendt 2012).

Horses' ability to sense moods, emotions and needs of others, which Blake (2007) calls "communication beyond senses" and "reading of thoughts", resembles Stern's (1998) definition of inter-subjective communication. "Being attuned to each other, reading each other's gestures, comes naturally in reciprocal relationship where intentions are shared" (De Georgio \& De Georgio-Schoorl 2016, 38).

A horse learns from emotional consequences of her/his behaviour (Wendt 2012), and, similarly to humans, "negotiates meanings" (learns) by connecting past and present experiences (Fredriksen 2011a; 2011b). Horses are able to share experiences and learn from each other, for instance by observing and mimicking (De Georgio \& De Georgio-Schoorl 2016). Like children, foals learn through trial and error (Wendt 2011) and when a trial leads to success, further explorative behaviour is motivated by the experience of mastery (Dewey 2005; Fredriksen 2011). In contrast, if a trial ends with negative consequences, pain or emotional distress, a horse will remember that well. Repeatedly experienced failure, disrespect or unfair treatment, in both humans and horses, might affect their quality of life and motivation to learn. Encouragement and support from their companions or teachers can help them regain curiosity and positive attitude.

\section{Epistemology, methodology and methods}

\subsection{Post-human epistemology}

Post-humanist epistemology promotes more holistic, transdisciplinary knowledge construction that "produces situated, material, interconnected, processual, and affirmative knowledges" (Ulmer 2017, 836). Building on an epistemology that goes beyond human-centered understanding of knowledge, this article proposes that renewed understanding of learning and teaching can be achieved through intersubjective interactions among more-than-human individuals, more precisely through "interspecies pedagogy". The term "interspecies pedagogy" refers to processes of less anthropocentric teaching and learning across species where perspectives of all involved subjects are respected 
and taken into consideration. Pedagogy is a broad field that originally deals with human learning, teaching, knowledge and development. Even though it represents anthropocentric discourse, pedagogy does not have to lead to the development of anthropocentric knowledge (Hagström 2018). The two words "interspecies" and "pedagogy" point to the appreciation of the process of co-learning and co-teaching among different species in a non-anthropocentric manner. Still, the concept "interspecies pedagogy" that was developed for this article can hardly break completely free from the anthropocentric discourse that pedagogy is rooted in. The purpose of my study was to learn from my horse, but the interpretations of what was learned were applied to the understanding of human teaching. Therefore I can not claim that interspecies pedagogy is a nonanthropocentric term. It can rather be seen as a continuation of contemporary trends to include the agencies of physical environments, materials and more-than-human beings in intra-active pedagogies (Lenz Taguchi et al. 2010).

Movements away from the traditional one-way transmission of knowledge are not new (see for instance the work of Dewey in the early 1900s), but due to pressure from neo-liberalism, traditional teaching seems to be returning to schools. The contemporary trend with focus on external measurements is rising (Robinson 2016) despite the fact that it is now, more than ever, important to acknowledge and advocate for the co-existence of more-than-humans on our planet. Environmental challenges require more imaginative, creative, courageous and radical forms of knowledge development (Jickling \& Sterling 2017). The case of interspecies pedagogy presented in this article is an attempt to learn about teaching from a horse.

At the beginning of my study with my horse, in 2014, I was not familiar with critique of anthropocentrism, nor was I an experienced horse-person. I was trying to learn from equestrian literature, seeking advice from horse trainers and grappling with how to understand Zvekki's and my relationship. The study has initiated a transformational process of becoming-with my horse (Haraway, 2008).This article presents some of the knowledge that I gained through our joint experiences, especially those experiences that can be characterised as challenging, disruptive, surprising or emotionally loaded. "Educational experiences that are held, felt, and disruptive might just be the basis for learning that is, indeed, transformational" (Jickling 2017, 28). The new knowledge from encounters with Zvekki has helped me develop a sense of ecological awareness that has already started to influence my teaching of university students. 


\subsection{Arts-based methodology}

The study presented here is based on qualitative, ethnographic and participatory methods. It is influenced by my professional and personal interests and agendas, as any study is influenced by its researcher (Stake 2010). A researcher's subjectivities and connoisseur skills are valuable assets in qualitative inquiry (Eisner 1991). My experiences of teaching Art \& Craft in early childhood teacher education, and from studies where young children were my co-researchers, have contributed to this study where my horse was my co-researcher. My research with children was directed towards better understanding of experiential learning through arts-based research methodology (ABR). The same methodology has influenced my approach to the study with Zvekki. $A B R$ originally emerged from social science research that is contextual, practice-driven and often ethnographic. ABR is recognised for its appreciation of individual uniqueness and creativity, celebration of aesthetic sensibilities and emotional engagement, as well as the demands it places on continual ethical considerations during the research process (Bresler 2006).

Arts-based researchers apply their emotions, body and senses in their research (Finley 2008) and see experience, imagination and cognition as integrated forms of knowing. This works best if the researchers remain aware of the emerging configurations and make appropriate adjustments accordingly (Eisner 1991). The nature of intersubjective relations "require(s) of the researcher that he or she stands in the fullness of life, in the midst of the world of living relations and shared situations" (Van Manen 1997, 32).

$A B R$ often addresses puzzling issues and ventures in the direction of justice and empowerment of the underprivileged. It has been described as "revolutionary" based on the understanding that recognising aesthetic ways of knowing in research "is an act of rebellion against the monolithic 'truth' that science is supposed to entail" (Finley 2008 , 73). Even though ABR has usually addressed phenomena concerning humans, a number of recent $A B R$ studies have addressed more-than-human perspectives (see for instance Hagström 2018; Fawcett \& Johnson 2019, Flowers et al. 2014; Bastian et al. 2017). "Arts-based methodologies provide alternative points of view about the emotional friction of human exceptionalism" (Fawcett \& Johnson 2019, 189) and can therefore contribute with critical and pioneering perspectives.

ABR often applies narratives - "vignettes" - as a form of communicating "research results" particularly because evocative language can present a researcher's lived experiences. Contextualised descriptions and poetic forms of language have the ca- 
pacity to evoke readers' empathic understanding (Barone and Eisner 2006). All of the mentioned qualities of $A B R$, enriched by post-human ontology, have shaped my understanding or my researcher role. In line with $A B R$, my study with Zvekki is contextual, acknowledges our subjectivities, operates on a micro-level, and presents "results" in the form of short narratives.

\subsection{Introducing Zvekki}

As neo-Darwinists pose, "each individual is a discrete, bounded and enumerable entity, one of population of such entities" (Ingold 2013b, 13). Zvekki's personality has been influenced by her environmental, biological and social backgrounds. She was born in the countryside in Serbia, exposed to local natural surroundings for the first four years of her life, before she moved 3000 kilometres north in the summer of 2013. She then first learnt to cope with bare rocks, extensive rains and other natural characteristics of her new environment. Regarding her social life, moving to another culture also exposed her to unfamiliar demands and expectations from humans due to dissimilar ways of horse keeping in the two cultures.

Genetically, as a mixed breed, Zvekki was not bred or trained for any specific type of performance in the service of people. Considering her independence and food finding skills, she seems to resemble a wild horse with the ability to survive without people. When I met her, as a three-year-old, Zvekki was, as she still is today, curious and self-confident with vivid inner motivation to act upon her environment. She seldom runs away from unfamiliar objects, but rather approaches them with curiosity, pushing them and waiting for a response. She would more likely fight back than run away when someone or something confronts her. This could be a valuable ability in the wild, but her resemblance to an untamed horse also makes her potentially dangerous to people, especially when she is misunderstood or treated "unfairly". She seems to have an extremely strong sense of fairness and justice. She communicates with a wide range of embodied signals and demands to be respected and listened to. Zvekki is a rebellious horse that resists being "contaminated by humans".

\subsection{Interspecies pedagogy - Zvekki and I}

Zvekki and I have known each other since June 2012 and been in everyday contact from July 2013, except for three and a half months of separation from October 12th 2013 to February 1st 2014. Data for this article has been generated from my encounters with 
Zvekki over the years of our everyday contact. Similar to an ethnography, where one studies a certain setting over a long period of time, I have been studying our interactions since the 1st of February 2014. Interspecies pedagogy involves a method whose form is similar to participatory observation, or rather More-Than-Human Participatory Research (Bastian et al. 2017). Additionally, interspecies pedagogy studies contexts where some kind of mutual pedagogical activity is taking place between more-thanhumans. Observation notes from Zvekki's and my daily encounters from the beginning of February 2014 to the end of December 2014 provide the main data source for this article.

Zvekki and I had a friendly relationship before I unfortunately had to leave her for more than three months (Fulbright research visit to the USA). The separation took place shortly after she had arrived in Norway. I knew that the timing of my absence was inconvenient, but Zvekki was left with experienced horse owners and I trusted them to take good care of her. That was what they did, but in ways unfamiliar to Zvekki. She did not understand what the people expected from her. During the three months, she had become emotionally disturbed and dangerous. She was biting, kicking and attacking people. She had not just become a "time bomb" (De Georgio \& DeGeorgio-Schoorl 2016), but was also frequently exploding. Today I understand that her disturbing behaviour was probably a result of living in an unfamiliar setting that lacked the conditions to support her creativity and failed to acknowledge her cognitive and emotional life (De Georgio \& DeGeorgio-Schoorl 2016).

The notes written in 2014 described the most significant experiences, emerging issues, surprises and misunderstandings. Such misunderstandings or "breakdowns in understanding" had the potential to uncover what is usually overlooked or taken for granted (Brinkmann 2014, 724). The process of "prolonged engagement" (Bresler 2006) in becoming-with Zvekki exposed me to a constant flow of challenges, dangers and "breakdowns in understanding", as well as facilitated numerous "spaces for wonder" (Hagström 2018).

The notes from our encounters have been rewritten into short narratives that might represent a form of "knowing from the inside", from our shared experiences (Ingold 2013a, 5). I tried to understand Zvekki through my embodied presence. However, it is an ethical challenge to claim that we can "know" another individual. We can never really "know" another individual - thus, a relationship offers possibilities for "liminal intimacy" (Nimmo 2016). My notes and narratives are certainly coloured by my interpretative voice, my agendas, subjectivities and bias. Inclusion of more-than-human subjects in research also raises puzzling ethical questions (Bastien et al. 2017). I hope that my 
representations of Zvekki are just, but I will never know how she would experience my representations of her. For this article, I have chosen six short narratives that can shed light on the research question: Which characteristics of more-than-human learner's experience should be taken into consideration by teachers who seek to facilitate meaningful learning conditions? The following section presents these narratives structured into two themes: "negative experiences" and "Zvekki's creativity".

\section{Empirical examples}

\subsection{Theme: Negative experiences}

\section{A dangerous beast}

I was very excited to meet my horse after three months of separation. I was told that she had become difficult, and I did not know how she would respond to meeting me again. I decided to sneak into her field and stand next to a big fallen oak trunk - a potential place I could jump behind in case she attacked me. When I called her name, she responded immediately with a neigh and started to gallop to meet me. Her ears were curiously turned toward me, she seemed happy and there was no doubt that she had recognised me. Then, she suddenly stopped about 15 meters away and looked at me for a few seconds. Then she lowered her head almost to the ground, and with her ears turned backwards started an attack. I still stood on the same spot, but was scared to death. I was struggling with how to respond: should I run away or jump behind the oak trunk, although I knew that the wisest thing to do was not to move? Standing there was very hard and scary, but that was my chance to show her that I believed that there was still some good in her. She stopped her attack only a meter away from me. I stretched out my arm, let her smell my hand and gave her a carrot. While she was chewing, I slowly retreated towards the fence, keeping her in my sight and hoping that she would not follow me.

\section{Refusing to move in circles}

Training a riding horse often starts with teaching her/him to move around a person standing in the middle. Riding training is usually performed in a work paddock, where a horse is expected to move around and around in circles. As long as I have known Zve$\mathrm{kki}$, she has hated moving in circles. Even simply bringing her into a space constrained by fence or walls would annoy her. She seems to find it meaningless: What is the point of moving when one arrives back at the same place? She has always preferred moving 
in open landscapes. Most equestrians would see Zvekki's discomfort with work paddocks as disobedience and would not take it seriously. I respected Zvekki's discomfort with work paddocks and did not want to pressure her, but when we sometimes had riding instructions from a horse trainer, we had to be in a paddock. The lessons usually ended earlier than the full time we paid for - we abandoned the paddock when I sensed that Zvekki's patience was coming to an end. However sympathetic the trainers were, I never managed to make them completely understand Zvekki and me. A sense of embarrassment was always present. They would say: "You know you have to win over the horse!", but I knew that if I demanded more from Zvekki, I would not win but lose her trust.

I was told that Zvekki, during my absence, threw her rider in a work paddock where she was forced to canter in circles. The rider was experienced and not easy to dislodge, but Zvekki was creative and kneeled down on her front legs. Something similar happened when another experienced rider fell off Zvekki and broke her spine. These two incidences had a significant impact on her reputation as a horse that should not be trusted.

\section{Stomach pain}

"Azoturia" is a painful condition of muscle cramp that can suddenly occur due to chemical reactions in a horse body. It had been confirmed by a veterinarian that Zvekki had experienced such pain, which made her hypersensitive to being touched on her stomach. One of the occasions when she did not let me touch her, she was tied in a stable hallway facing the main gate. Her friend, a black Dole horse called Lillemor, was tied in front of her, also facing the gate. I was standing on Zvekki's right hand side and brushing her, when she responded with anger and kicking toward me with her rear leg. Such rejections to touching her stomach continued for days. I supposed she was in pain, but strangely, she did not seem to be in pain when she was standing in other places than in the stable hallway.

A few days later, when Lillemor and Zvekki stood in the same hallway, but Lillemor was facing a different direction, Zvekki was not in pain any longer. The following day, she again did not let me brush her stomach. I now turned her around, so that the main gate was behind her, and the pain stopped. I cannot know what she was experiencing, but realized that her expressions of pain were there only in the specific physical contexts (Lillemor's position, gate position, my position in relation to her body etc.) that had most likely been the same as the contexts in which she experienced pain from azoturia for the first time. 


\subsection{Theme: Zvekki's creativity}

\section{Blowing a whistle}

The first time I noticed Zvekki's creative abilities was after I had known her for a few weeks. She was walking around and whistling. I was surprised: Can horses whistle? Then I realised that she had a short plastic tube in her mouth through which she was blowing with amusement. This incident took place shortly after she had learned how to use an automatic horse dinking-trough. On one occasion the water hose for the water supply was removed (to water flowers), but a short plastic tube for a hose connection was left in the trough. Zvekki obviously realised she could use the tube for something amusing. She discovered affordances (Gibson 1979) of this little object that I had never thought of. She pulled the little tube off the drinking trough connection, placed it between her front teeth, closed her lips around it, and whistled!

\section{Pointing with rear legs}

Everyone was afraid of Zvekki's rear legs. They could kick hard, especially the left leg, marked with a white sock. That leg could push away someone unfamiliar trying to brush her tail, or if someone she did not trust stood too close. I have been afraid of that leg for months, but have come to realise that her control of her legs is much more nuanced than I initially thought. People often assume that a horse is mean when swinging around with her/his hind legs. Once, after Zvekki had been out in the rain, I took her indoors and started to dry her with a towel. She usually liked to be dried, but this time she started to kick out with her white-socked-leg. I was surprised. I could usually stand still with a towel in my hands and she would dry her own head, ears and neck, but not this time. I shied away and I observed her movements more closely. I realised that she was not trying to kick me but was lifting her hoof up to her own stomach, exactly to the point where a stripe of rainwater was sliding along her body. I now understood that this was obviously uncomfortable and she wanted me to dry her exactly there with the towel. This episode made me reconsider my interpretations of her leg movements. When I started to pay closer attention to her body language, I realised that she often used her hind leg for communication, both to warn people who did something she didn't like, and for pointing, similar to how humans might use a forefinger.

\section{Repairing a hut roof}

Zvekki has a small hut in her field where she can shelter from rain, snow or heat. The hut is a metal construction and the sides are covered with tent textiles. The roof is covered 
by tared paper that sometimes needs to be repaired, especially in windy weather. One autumn day I repaired the roof by climbing on the metal construction and stretching the tared paper, while Zvekki was watching me. The next day I realised that the tared paper was curled up again, even though it was not windy any more. I asked the other horse owners in the stable if they had any idea about who had been messing with the roof, but when I examined the hut closely, I noticed muddy hoof prints and holes from horseshoe studs in the hut wall. This was a certain sign that Zvekki had been climbing up, standing on her hind legs, supporting herself with her front legs and trying to "fix the roof". She could have reached the edges of the roof by simply lifting her head, still she chose to act in such an unusual manner. This was surprising, but not unbelievable Zvekki had been imitating my actions also on other occasions.

\section{Discussions: What did Zvekki teach me?}

The six examples of real-life events shed light on diverse characteristics of Zvekki's and my experiences. The examples will be treated collectively in the following section. The five themes that structure this section (5.1-5.5) emerged from the examples and represent possible answers to the following question: Which characteristics of morethan-human learner's experience should be taken into consideration by teachers who seek to facilitate meaningful learning conditions?

\subsection{Influence of past experiences and emotions}

"The past is never left behind, never finished once and for all" (Barad, 2007, p. 234). Teachers that focus on teaching outcomes often ignore past experiences of their morethan-human students, but what is possible to learn depends on the affective values of these experiences (Sterling 2011). We usually don't know our students' experiences - most times we do not even remember our own experiences - yet emotional experiences from the past keep haunting our present negotiations of meaning (Fredriksen 2011b). Zvekki obviously had some negative past experiences from a work paddock, since simply the sight of a fenced space could trigger her negative reactions. Through intra-actions with her physical environment (Barad 2007) she sensed what might have been expected from her in such a space, and she immediately showed signs of discomfort. The example of "stomach pain" also shows how everything (other horses, physical environment, my standing position, etc.) could influence her interpretations of what might happen next. She was sensitive to nuanced qualities of present contexts and if 
something reminded her of similar qualities in her past experiences, she quickly entered a parallel emotional mood (Wendt 2012).

When Zvekki and I met after a long separation period, she seemed to be reminded of two conflicting past experiences: at first she seemed to be happy to see me, then she possibly remembered that she had stopped trusting humans, and I was one of them. Both times she stopped her attack and took a few seconds to think. When she reached me, she did not push or bite me - that would have scared me even more than she already had. Today, I am glad I did not run away or fight back, but rather remained standing still. The choices of us both, that neither I nor she went too far in scaring the other one or being scared, opened a window for our future possibility to regain trust.

Most of the time I did not know what kinds of human actions had made Zvekki unhappy in the past, yet I had to make sure that I did not repeat them. That would only reinforce her negative reactions. Trying to avoid provoking Zvekki demanded extraordinary attention to her body language in order to notice the first signs of irritation. In order to prevent the "time bomb explosions" (De Georgio \& DeGeorgio-Schoorl 2016), I had to be able to sense and match her moods and emotions (Herskind 2008). To be able to do so, I had to improve my inter-subjective abilities; I had to, because I could be injured if I did not. The process of "becoming-with" (Haraway 2008) Zvekki also forced me into becoming more self-confident and creative.

During our encounters in 2014 , I was constantly afraid that she would hurt me. In her darkest days, Zvekki did not show any empathy. I knew that it was not wise to be afraid, because she took advantage of my weakness. Zvekki sensed my fear, irrespective of how hard I tried to hide it. Since I could not pretend to be strong, I actually had to be self-confident, so that she could respect me.

In teaching humans, we often rely on telling them what to do, how to think, or even what to feel. But saying: “Don't be afraid!" can't really change how someone feels. Instead, we have to provide conditions for transformative experiences - it is indeed the positive educational experience that has the power to transform (Jickling 2017). A teacher who wants to facilitate motivating conditions for learning should consider the students' experiences and emotional state and provide conditions for positive learning experiences.

\subsection{Contexuality of an experience}

My realisation that Zvekki's stomach pain was present only in a specific physical context made me wonder about the relations between experiences and their contexts. 
Every experience is contextual, every interaction situational (De Georgio \& DeGeorgioSchoorl 2016, 110). Zvekki showed me that qualities of physical contexts were significant for activating her past negative experiences. She did not seem to be able to forget these experiences easily. What could I do to help her gain positive experiences that could shadow the bad ones? In order to transform her reactive energy, it was important to facilitate conditions where Zvekki could "center herself on an emotional-cognitive level" (De Georgio \& DeGeorgio-Schoorl 2016, 71). I had to provide the conditions where she did not have to worry or be defensive, and where she could experience something pleasant.

How does one turn negative experiences into positive? When Zvekki was overpowered by negative experiences from her past, I had to be able to create conditions where she could gain positive experience from a similar context. However, there was always a risk of creating contexts that were too similar to her negative experiences. To avoid reinforcing her negative emotions like this, I leaned on intra-active pedagogy and trusted that changing physical contexts would make the new situations less similar to those in which negative experiences, in the past, found a place. For instance, we could ride in a circle if there were no fences, if the circle was much larger (around a field), if it was not completely round (amidst an open landscape) and should never repeat the circular movement twice in the same direction. In a similar way, when my human students exclaim, "I cannot draw!", I know it does not help encouraging them verbally. Instead, I have to facilitate conditions where they can experience mastery with a new drawing experience. In order not to reinforce their negative experiences from the past, I help them engage in some unusual drawing experience (drawing without looking at the paper, drawing upside-down, or similar) that could destabilise their automatised negative reactions to activities of drawing.

\subsection{Appropriate level of challenge}

After our reunion, Zvekki had to learn everything again. I could not interact with her in the ways we used to a few months earlier. I had to be attuned to her emotional state and act accordingly. Our steps in regaining her self-confidence and confidence in humans had to be tiny. I knew that I should never ask her for more than she was willing to give. Thus, instead of asking her, I rather provided conditions where she could be motivated. I know that giving treats to horses is neither accepted in equestrian or in zooanthropocentric culture, but in Zvekki's case, food was the only positive thing in her life at the time. I used carrots to create some positive experiences. Her condition 
was so bad that even taking a carrot from my hand without biting was an experience of mastery both for her and for me.

The tiny steps in our new relationship had purpose: to ensure her an experience of mastery that would, in turn, motivate her urge for more positive experiences (Eckhoff 2008). I had to be very careful not to ask for too much; that could easily provoke her, end up as a negative experience and disturb our process of developing trust. However, if I asked too little from her, she seemed to find that disrespectful. As with humans, both challenge and mastery had to support her self-confidence and facilitate growth (Eisner 2002). She wanted challenges, but the level of each challenge had to be exact: it had to be an appropriate challenge in that given moment and it had to have good potential for mastery.

"The art of the interaction is to keep it a cognitive experience: long enough to prevent misunderstandings, short enough to avoid creating confusion" (De Georgio \& DeGeorgio-Schoorl 2016, 57). Both horses and children "need a socio-cognitive environment in which they have the space and time to develop their own interests, make subjective experiences, break for latent learning processes or withdraw before the situation becomes too much and/or reactive" (Spannring 2019, 16).

Being able to imagine what appropriate challenge for Zvekki could be was a challenging task. It demanded that I became even more familiar with Zvekki's attitudes, emotions, gestures and body language. I had to be attentive to her attention. In order to understand her needs better I had to try to see the world from her point of view, mirror her emotions, interests and intentions (Stern 2003). Learning to be a good teacher is about learning to maintain attention, so that one can be there when one's student is there (Austen 2014).

It was a sign of health when Zvekki started to take initiative in communicating and exploring. On the occasion when she pointed at her stomach in order to ask me to dry her, I was unprepared for such an initiative from her. My immediate reaction was therefore to move away in order not to be kicked. Fortunately, I did not quit trying to understand her perspective and looked more closely into the nuanced qualities of the specific context and her specific leg movement.

Teachers need to be curious, creative and patient in their efforts to understand their students' points of view. However, teachers' knowledge and experiences sometimes prevent them from seeing. Zvekki had no chance of telling me what to look at. It was my responsibility to pay close attention, to connect to her inter-subjectively and emphatically interpret what she was trying to "say". Zvekki taught me that it is my responsibility to try to understand the perspectives of those I teach. 


\subsection{Respect for learners' advocacies}

Horses' advocacy is highly regarded in some cultures (Davis \& Maurstad 2016b). Unfortunately, most people prefer horses that do not think or make decisions on their own. However, it is only when a horse's subjectivity and advocacy is acknowledged, that the horse will be internally motivated to act and learn (De Georgio \& DeGeorgio-Schoorl 2016). This is similar to children's learning: genuine curiosity and intrinsic motivation makes learning meaningful (Spannring 2019), while training for the purpose of others can be experienced as meaningless. Zvekki is a horse who refuses to do things that are not meaningful to her. Respecting horses' subjectivities means to let them "be actual protagonists in interactions as free agents and not merely as puppets moved by strings" (De Georgio \& DeGeorgio-Schoorl 2016, 58). I am sure that Zvekki could sense when I welcomed her advocacy. She could sense when I was listening to her, both to the whistling sounds, to the swinging of her legs and rotations of her ears. I would laugh at her creative discoveries, and never punished her for creative actions. I think she notices that too.

"Everything around us can play a role in the experience and we can never know, precisely, what will be part of the experience" (De Georgio \& DeGeorgio-Schoorl 2016, 83). The examples from the whistle blowing and the reparation of the roof make visible Zvekki's exquisite sense for details and ability to notice affordances of objects around her. What a certain object could afford depended on her curiosity and imagination (Fredriksen 2011). Inner motivation to explore, present in healthy horses (De Georgio \& DeGeorgio-Schoorl 2016), led Zvekki to discoveries similar to those I have observed in young children's explorations of materials (Fredriksen 2011). Discovering hidden affordances of objects is fun and motivates further explorations. However, it was first when Zvekki came into a cognitive (and not a reactive) frame of mind (De Georgio \& De Georgio-Schoorl 2016) that she was motivated to engage with explorative, selfinitiated play with no expectations from the outside.

Acknowledging horses' advocacy requires a questioning of power between horses and their human companions. In the case of Zvekki and me, she was the most powerful in our relationship after our reunion. Her physical dominance, temporary absence of compassion for others and lack of self-confidence made her potentially dangerous. Our power balance had to be negotiated over the following years. I had to earn respect from her, in a similar way as she acquired mine.

Recognising a horse, or child, as a cognitive being starts with acknowledging their subjectivities, emotions and senses (De Georgio \& DeGeorgio-Schoorl 2016). In 
order to share experiences with a horse we need to "switch from focusing on our own world of perception, senses, and inner state, to that of the horse" (De Georgio \& DeGeorgio-Schoorl 2016, 61), and "we have to abandon our expectations and need of control" (De Georgio \& DeGeorgio-Schoorl 2016, 36). Both horses and children become numb and apathetic when their will to act, individuality and creativity are ignored. Motivating teachers show respect for their students' uniqueness, appreciate their personal voices and celebrate their creativity.

\subsection{Mutual trust and confidence}

When Zvekki was emotionally disturbed, she did not seem to trust anyone and had to take all of her decisions herself. That is why she was not easy to walk with, feed or brush. The process of trying to help her included my efforts to convince her that she needed to share some of her decision making with me. However, this transition was not easy, because she first needed to trust me in order to let me decide for her. Animals learn in a similar way to humans: "through listening, imitating, and experiencing their family and friends" (Bradshaw 2010, 413). Children imitate their significant others those they trust. When Zvekki started to imitate my actions that was a sign of trust and interest in my actions. The examples of whistling and repairing the hut roof show how she both learned from direct explorations of her physical environment and from imitating humans. Imitating someone with different body shape is a challenge that requires creativity.

"Being attuned to each other, reading each other's gestures, comes naturally in a reciprocal relationship where intentions are shared" (De Georgio \& DeGeorgio-Schoorl 2016, 38). Being inspired by another's perception facilitates a dialogue (De Georgio \& DeGeorgio-Schoorl 2016). Such dialogue can have different modes. Being highly intelligent, horses are able to learn human signs (Wendt 2012); however, Zvekki required me to learn her signs. She even created new signs to communicate with me. As a creative individual, Zvekki seemed to know how she could learn (Blake 2010), and how she could teach.

When Zvekki and I re-united she seemed unhappy. After years of being loved, no-one showed affection for her for more than three months. Instead, people showed her anger and fear. She did not know that they were irritated that she was not fulfilling their expectation; she did not know what they were expecting from her. When I returned to her, I wanted her to trust me, but trust had to be earned. This is similar with human students: time is needed in order to get to know each other better and to devel- 
op trust (Fredriksen, Nordbø \& Cruz 2016). Each more-than-human student needs to be seen and acknowledged as a unique individual with one's own subjectivities, talents and fears. With trust also care, compassion and respect can be developed. "We can only be ethical in relation to someone we can see, understand and love" (Jickling 2017, 23). Empathy is a way of understanding and is essential in teaching. Trusting one's teacher is necessary if students are to embrace challenges the teacher exposes them to (Fredriksen, Nordbø \& Cruz 2016). In contrast, if students suspect their teacher not to be considerate of their wellbeing, they might feel insecure and distrustful. This could, in turn, prevent them from learning. A teacher needs to be able to challenge their students appropriately and in non-confrontational manners. Mutual trust is a precondition for meaningful and motivating learning contexts.

\section{Final words}

As an anthropocentric institution, education tends to reinforce the established dichotomy and power division between human and non-human animals and seeks to sustain the production and consumption of animals in the service of humans (Pedersen 2010). If we acknowledge the educational domain as co-constructed through entangled experiences with other species, we might be able to accept that other animals can be our teachers (Spannring 2017, 67). Listening to other-than-human animals can remind us about the important role that emotions, attention to our environments, and creative attitudes have for maintaining life on this shared Earth.

When education is directed towards productivity, efficacy and types of uniformed quality, we tend to ignore individuals' experiences in teaching and learning. As teachers, we might become unable to grasp what each student and each context can contribute. Attention to details is essential for what we, or our students, can come to experience, learn and become.

By giving a voice to one horse, this text makes the voices of other animals a little bit more audible. As one horse trainer said: too much focus on teaching techniques makes a horse invisible (Rashid 2011). The same can be said about teaching students: focusing on following pre-defined methods and plans can prevent us from noticing our students' experiences. Too much focus on outcomes obscures our ability to notice valuable learning experiences during the process.

Exposing oneself to contacts with more-than-humans, engaging with them and realising how similar we are, can initiate mutual compassion. It is through caring about our environment and other species that we can come to question the limitation of an- 
thropocentrism. Compassion for more-than-humans is one way to overcome the divide between the human and non-human (Bekoff 2013), which is necessary for understanding of ecological challenges of our times. "Humans have never before witnessed this kind of epochal shift or had to accept this scale of responsibility" (Jickling \& Sterling 2017 , 9). We have to start listening to what other-than-humans can teach us and stop ignoring the nature within ourselves.

\section{REFERENCES}

Armstrong, P. \& Simmons, L. 2007. "Bestiary: An Introduction.” In L. Simmons \& P. Armstrong (eds.), Knowing animals, Leiden, Boston: Brill, 1-24

Aspelin, J. 2010. "What really matters is 'between'. Understanding the focal point of education from an inter-human perpective." Education Inquiry, 1(2), 127-136.

Austen, H. 2014. Artistry unleashed: A guide to pursuing great performance in work and life. Toronto: University of Toronto Press.

Barad, K. 2007. Meeting the universe halfway: Quantum physics and the entanglement of matter and meaning. Durham: Duke University Press.

Barone, T. \& Eisner, E. W. 2006. "Arts-based educational research". In J. L. Green, G. Camilli, P. B. Elmore, A. Skukauskaite \& E. Grace (eds.), Handbook of complementary methods in education research, Mahwah: Lawrence Erlbaum, 95-109.

Bastian, M., Jones, O., Morre, N. \& Roe, E. (eds.). 2017. Participatory research in morethan-human worlds. Abingdon: Routledge.

Bekoff, M. (ed.). 2013. Ignoring nature no more: The case for compassionate conservation. Chicago: University of Chicago Press.

Biesta, G. J. J. 2013. The beautiful risk of education. Boulder: Paradigm Publ.

Birke, L. 2017. "Meeting points: Choreographies of horses and humans." TRACE: Finnish journal for human-animal studies, 3, 54-70.

Blake, H. 2007 (1975). Talking with horses: A study of communication between man and horse. London: Souvenir Press.

Blake, H. 2010 (1979). Sunt hestevett [Horse sense]. Oslo: Tun Forlag.

Bradshaw, G. A. 2009. Elephants on the edge: What animals teach us about humanity. New Haven Yale University Press.

Bradshaw, G. 2010. "You see me, but do you hear me? The science and sensibility of trans-species dialogue." Feminism \& Psychology, 20(3), 407-419. 
Braidotti, R. 2002. Metamorphoses: Towards a materialist theory of becoming. Cambridge: Polity.

Bresler, L. 2006. "Toward connectedness: Aesthetically based research." Studies in Art Education: A Journal of Issues and Research in Art Education, 48(1), 52-69.

Brinkmann, S. 2014. “Doing without data." Qualitative Inquiry, 20(6), 720-725.

Davis, D. L. \& Maurstad, A. 2016a. "Biosocial encounters and the meaning of horses." In D. L. Davis \& A. Maurstad (eds.), The meaning of horses: Biosocial encounters. New York: Routledge.

Davis, D. L. \& Maurstad, A. (eds.) 2016b. The meaning of horses: Biosocial encounters. New York: Routledge.

De Georgio, F. \& De Georgio-Schoorl, J. 2016. Equus lost? How we mistunderstand the nature of the horse-human relationship - plus, brave new ideas for the future. North Pomfret, Vermont: Trafalgar Square.

Dewey, J. 2005 (1934). Art as experience. New York: Berkley Publishing Group.

Dissanayake, E. 2007. "In the beginning: Plastocene and infant aesthetics and 21stcentury education in the arts." In L. Bresler (ed.), International handbook of research in arts education, Dordrecht: Springer, 783-797.

Eckhoff, A. 2008. "The importance of art viewing experiences in early childhood visual arts: The exploration of a master art teacher's strategies for meaningful early arts experience." Early Childhood Education Journal, 35, 463-472.

Eisner, E. W. 1991. The enlightened eye: Qualitative inquiry and the enhancement of educational practice. New York: Macmillan Publ. Co.

Eisner, E. W. 2002. The arts and the creation of mind. New Haven: Yale University Press.

Fawcett, L. \& Johnson, M. 2019. "Coexisting entities in multispecies worlds: Arts-based methodologies for decolonial pedagogies." In T. Lloro-Bidart \& V. S. Banschbach (eds.), Animals in environmental education, Cham: Springer, 175-193.

Feinberg, W. \& Soltis, J. F. 2009. School and society. New York: Teachers College Press.

Finley, S. 2008. "Arts-based research.” In G. J. Knowles \& A. L. Cole (eds.), Handbook of the arts in qualitative research, New Angeles, London, New Delhi, Singapore: Sage Publications, 71-81.

Flyvbjerg, B. 1992. Rationalitet og magt. Copenhagen: Akademisk Forlag.

Fox, K. 2008. "Rethinking experience: What do we mean by this word 'experience'?" Journal of Experiential Education, 31(1), 36-54.

Fredriksen, B. C. 2011a. Negotiating grasp: Embodied experience with three-dimensional materials and the negotiation of meaning in early childhood education. Oslo: The Oslo 
School of Architecture and Design.

Fredriksen, B. C. 2011b. "When past and new experiences meet: Negotiating meaning with 3-D materials in early childhood education." FORMakademisk, 4(1), 65-80.

Fredriksen, B. C. 2012. "Providing materials and spaces for the negotiation of meaning in explorative play: Teachers' responsibilities." Education Inquiry, 3(3), 331-347.

Fredriksen, B. C. 2016a. "Learning to learn: What can be learned from firsthand experience with materials?" Paper presented at the 2016 Design Research Society, Brighton, UK.

Fredriksen, B. C. 2016b. "Attention on the edge: Ability to notice as necessity of learning, teaching and survival." Visual Inquiry: Learning and teaching art, 5(1), 105-114.

Fredriksen, B. C. 2017. "Cultivating eco-creativity: The seeds of ecological responsibility in hands of Norwegian early childhood teachers." In H.-B. Holmarsdottir \& S. L. Bastien (eds.), Youth as architects of change: Global efforts to advance youth-driven innovation for social change, New York: Palgrave Macmillan, 243-275.

Fredriksen, B. C. 2018. "Where is the body? Understanding children's first signs/representations from their point of view." In M. C. Connery, V. John-Steiner \& A. Marjanovic-Shane (eds.), Vygotsky and creativity: a cultural-historical approach to play, meaning making, and the arts, Second edition, New York: Peter Lang, 61-93.

Fredriksen, B. C., Nordbø, A. L. \& Cruz, F. 2016. "Trust me, you will learn something! Challenge and confidence in teaching improvisation." In M. Santi \& E. Zorzi (eds.), Education as Jazz, Cambridge: Cambridge Scholars Publishing, 139-158.

Gibson, J. J. 1979. The ecological approach to visual perception. Boston: Houghton Mifflin.

Haraway, D. 2008. When species meet. Minneapolis: University of Minnesota Press.

Herskind, M. 2008. "Movement analysis and identification of learning processes." In T. Schilhab, M. Juelskjær \& T. Moser (eds.), Learning bodies, Copenhagen: Danmarks Pædagogiske Universitetsforlag, 269-283.

Hagström, E. 2018. Mellan människa och häst: Djur-blivande i den pedagogiska relationens mellanrum [Between man and horse: Animal-prospective in the space of the educational relationship]. Doctoral thesis. Luleå: Luleå Tekniska Universitet.

Ingold, T. 2013a. Making: Anthropology, archeology, art and architecture. London and New York: Routledge.

Ingold, T. 2013b. “Prospect." In T. Ingold \& G. Palsson (eds.), Biosocial becomings: Intergrating social and biological anthropology, Cambridge: Cambridge University Press, $1-21$.

Jickling, B. 2017. "Education revisited: Creating educational experiences that are held, felt, and disruptive." In B. Jickling \& S. Sterling (eds.), Post-Sustainability and Envi- 
ronmental Education: remarking education for the future, Cham, Switzerland: Palgrave MacMillan, 15-30.

Jickling, B. \& Sterling, S. 2017. "Post-sustainability and environmental education: Framing issues." In B. Jickling \& S. Sterling (eds.), Post-sustainability and environmental education: remarking education for the future, Cham, Switzerland: Palgrave MacMillan, 1-11.

Lenz Taguchi, H., Moss, P. \& Dahlberg, G. 2010. Going beyond the theory: practice divide in early childhood education: Introducing an intra-active pedagogy. London: Routledge.

Merleau-Ponty, M. 1962. Phenomenology of perception. London: Routledge \& Kegan Paul.

Nimmo, R. 2016. "From over the horizon: Animal alterity and liminal intimacy beyond the anthropomorphic embrace." Otherness: Essays and Studies, 5(2), 13-45.

Orr, D. W. 2017. "Foreword." In B. Jickling \& S. Sterling (eds.), Post-sustainability and environmental education: remarking education for the future, Cham, Switzerland: Palgrave MacMillan, 1-11.

Pedersen, H. 2010. 'Is 'the posthumanism' educable? On the convergence of educational philosophy, animal studies, and posthumanism theory." Discourse: Studies in the Cultural Politics of Education, 32(2), 237-250.

Rashid, M. 2011. Horses Never Lie: The Heart of Passive Leadership. New York: Skyhorse Publishing.

Roberts, J. 2008. "From experience to neo-experiential education: Variations on a theme." Journal of Experiential Education, 31(1), 19-35.

Robinson, K. 2016. "Creative schools: The grassroots revolution that's transforming education." New York: Penguin Books.

Schuurman, N. \& Sireni, M. 2016. "The human horse relationship challenged by pregnancy and motherhood." In D. L. Davis \& A. Maurstad (eds.), The meaning of horses: Biosocial encounters. New York: Routledge.

Seaman, J. 2008. "Experience, reflect, critique: The end of the 'learning cycle' era." Journal of Experiential Education, 31(1), 3-18.

Shapiro, K. \& DeMello, M. 2010. "The state of human-animal studies." Society and Animals, 18(2010), 307-318.

Smith, K. 2011. "Professional development of teachers - A prerequisite for AfL to be successfully implemented in the classroom." Studies in Educational Evaluation, 37(2011), 55-61.

Spannring, R. 2017. "Animals in environmental education research." Environmental Education Research, 23(1), 63-74.

Spannring, R. 2019. "Ecological citizenship education and the consumption of animal subjectivity." Education Science, 9(1), 1-20. 
Stake, R. 2010. Qualitative research: Studying how things work. New York: Guilford Press.

Sterling, S. 2011. "Transformative learning and sustainability: Sketching the conceptual ground." Learning and Teaching in Higher Education, 5, 17-33.

Stern, D. N. 1998. The interpersonal world of the infant: A view from psychoanalysis and developmental psychology. London: Karnac.

Ulmer, J. B. 2017. "Posthumanism as research methodology: Inquiry in the Anthropocene." International Journal of Qualitative Studies in Education, 30(9), 832-848.

Van Manen, M. 1997. Researching lived experience: Human science for an action sensitive pedagogy. London: Althouse Press.

Wendt, M. 2011. How horses feel and think: understanding behaviour, emotions and intelligence. Richmond, UK: Cadmos Publishing.

Wendt, M. 2012. Tillit i stedet for dominans [Confidence instead of dominance]. Oslo: Pegasus forlag 